УдК 904 : 008 (091)

DOI: https://doi.org/10.33782/eminak2020.2(30).429

\title{
ИСТОРИКО-КУЛЬТУРНОЕ НАСЛЕДИЕ КАК СОЦИАЛЬНЫЙ ФЕНОМЕН
}

\author{
Леонид Грифбеен ${ }^{1}$, Надежда Рыюжева ${ }^{2}$ \\ ${ }^{1}$ Национальный историко-архитектурный музей «Киевская крепость» (Киев, Украина) \\ e-mail: lagrif@mail.ru \\ ORCID: https://orcid.org/0000-0002-3020-9636
${ }^{2}$ Николаевский национальный ун-тет имени В.А. Сухомлинского (Николаев, Украина) e-mail: ryzheva.nadiya@gmail.com
ORCID: https://orcid.org/0000-0001-8379-4325

У статті представлено дослідження соціальної природи історико-культурної спадщини. Показано, що воно характеризує об'єкти матеріальної культури минулого, які втратили своє первісне утилітарне призначення та перетворилися у матеріальні свідчення минулих культурних та історичних процесів. Сьогодні такі пам'ятники історії $i$ культури є носіями семантичної й аксіологічного інформації про дані процеси і тому, коли вони включені до сучасного культурного контексту, сприяють соціалізації індивідів.

Ключові слова: пам'яткознавство, історико-культурну спадщину, пам'ятники історії і культури, соціалізація індивіда, семантична інформація, аксіологічна інформація

Постановка проблемы. В наше время целый ряд социальных процессов значительно активизировал интерес различных слоев украинского общества к изучению и сохранению историко-культурного наследия, благодаря которому возможно осуществление адекватной реконструкции объективной картины исторического бытия народа1. Важной составной частью национального историко-культурного наследия являются памятники истории и культуры - как движимые, так и недвижимые. Поэтому возникает необходимость не только интенсификации практической деятельности в сфере охраны и использования памятников истории и культуры, но и разработки соответствующих теоретических основ, на которых основывалась бы такая деятельность, то есть исследований в области памятниковедения.

В наше время проблемы, связанные с материальным наследием прошлого, находятся в ведении особой науки - памятниковедения. В качестве отдельной науки оно оформилось только в последней трети XX ст. (хотя положения, касающиеся памятниковедческих проблем, высказывались достаточно давно). Памятниковедение быстро развивается, успешно завоевывает позиции среди других наук и имеет определенные результаты в решении как теоретических, так и практических задач, которые касаются нашего культурного достояния. Востребованность соответствующих знаний способствовала значительным успехам в обеспечении научных основ практической деятельности в области выявления, хранения и использования памятников истории и культуры. Однако результативность исследований теоретических основ данной науки требует активизации. Появление публикаций, посвященных

\footnotetext{
${ }^{1}$ Культурна спадщина як складова державної освітньо-виховної політики в Україні: Монографія / За заг. ред.: Н.М. Сенченко, М.О. Титової. Ніжин, 2019. 294 с.
} 


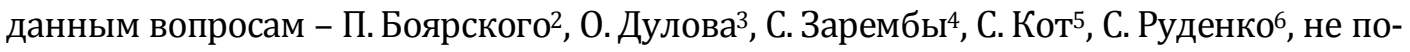
зволяет считать, что памятниковедение вполне четко определило свой научный статус и характерные особенности сравнительно с другими научными дисциплинами, в частности, с источниковедением ${ }^{7}$ Памятниковедение как наука определило объект исследования - культурное наследие, но оно еще не достигло полной определенности относительно наиболее существенных характеристик как социального явления.

Наиболее актуальным представляется необходимость четкого понимания самого феномена культурно-исторического наследия, которое должно базироваться на выявлении его функций и особого места в социальных процессах.

Цель работы - раскрыть значение историко-культурного наследия как социального феномена, показав его специфическую роль в социализации индивида.

Изложение основного материала. Общей тенденцией современных мировых цивилизаций становится спонтанный рост энтропии, которая характеризуется постоянным и неуклонным снижением уровня организации и девальвации энергий, присущих любым материальным образованиям, включая биологические. Поэтому каждое живое существо, стремясь сохраниться (а тем более развиваться), должно избавляться от энтропии ${ }^{8}$. Осуществление такого процесса предполагает взаимодействие с внешней средой. Австрийский физик-теоретик, один из создателей квантовой механики, лауреат Нобелевской премии Э.Шредингер считал, что живое существо получает от взаимодействия с внешней средой «отрицательную» энтропию - за счет выноса в нее же собственной «положительной» энтропии 9.

Отметим, что любое живое существо, чтобы «выносить» свою энтропию наружу, должно использовать как свойства определенной среды, так и иметь средства активного взаимодействия с ней. Для этого в структуре живых существ зафиксированы: с одной стороны, важные для них свойства среды, а с другой, существуют материальные средства взаимодействия с ней. С целью иллюстрации данного тезиса обратимся за примером к животному миру. Так, в центральной нервной системе хищника представлены соответствующие морфологические признаки (крепкие челюсти и быстрые ноги позволяют защититься от врагов и добыть пищу) и рефлексы, полученные частично генетически в наследство от предков, а частично приобретенные собственным опытом. В разных формах последнее касается всех живых существ, кроме человека.

В отличие от животных, человек приходит в мир «вооруженным» только незначительным количеством основных безусловных рефлексов, на основе которых решить задачу активного взаимодействия с внешней средой невозможно. Человек,

\footnotetext{
2 Боярский П.В. Введение в памятниковедение. Москва: Центр «Культура и Мировой океан», 1990. $218 \mathrm{c}$.

3 Дулов О. Пам'яткознавство як наука. Пам'ятки України. 1993. № 1-6. С. 139, 203-204.

${ }_{4}^{4}$ Заремба С.З. Українське пам'яткознавство: історія, теорія, сучасність. Київ, 1995. 289 с.

5 Кот С. Теоретичні проблеми пам'яткознавства. Пам'яткознавчі студії в Україні: теорія і практика. Київ, 2007. С. 7-64.

6 Руденко С.П. Про фундаментальні засади пам'яткознавства. Праці Центру пам'яткознавства. Вип. 14. Київ, 2008. С. 18-40.

${ }^{7}$ Антонович В. Лекції з джерелознавства / ред. М. Ковальський. Київ: Нац. ун-т «Острозька академія», 2003. 382 с.

8 Костюк В.Н. Изменяющиеся системы. Москва: Наука,1993. 344 с.

9 Шредингер Э. Что такое жизнь с точки зрения физика. Москва: Атомиздат, 1972. 62 с.
} 
сформированный как существо социальное, все остальное получает через общество. Это не только многоплановый комплекс знаний и навыков, выработанных обществом в процессе развития, но и сложный комплекс материально-технических средств, необходимых для взаимодействия с окружающей природой. Все новые поколения, каждый человек в отдельности получают от поколений предыдущих материальное и нематериальное наследие. В исторически последовательно сменяющихся периодах это становится для всех социальных образований той культурой, которая обеспечивает их существование и представляет собой все то, что характерно именно на данном конкретном этапе развития ${ }^{10}$. Следовательно, комплексное понимание культуры в ее идеальных и материальных проявлениях возможно только через все формы общественного сознания и общественную деятельность.

В данном контексте вполне закономерной и чрезвычайно актуальной становится задача определения, что представляет собой то культурное наследие, использованием, сохранением и хранением которого сегодня все больше озабочена общественность. Найти алгоритм решения данной задачи представляется возможным посредством выставления акцентов на особенностях и характерных чертах историкокультурного наследия как особого общественного явления, не тождественного всей имеющейся культуре, то есть на явлениях культуры, сохранившихся сегодня в том состоянии, которое они имели в свое исторически конкретное время.

В этом случае следует говорить только об относительной сохранности, поскольку течение времени отражается на всех памятниках истории и культуры, которые в более или менее аутентичном виде выдержали его воздействие. Что касается степени хронологической «удаленности», то в каждом конкретном случае она определяется самим обществом. Однако в любом случае речь идет о такой «удаленности» от современных реалий, когда сохранившиеся материальные предметы - результаты человеческой деятельности - уже не выполняют тех функции, ради которых общество их создавало.

Сохранившееся материальное наследие чрезвычайно актуально в процессе понимания социально-культурного развития. Такие материальные памятники, даже потеряв частично или полностью основные функции, продолжают представлять культуру определенного времени. Следовательно, они являются как свидетелями конкретных исторических событий, так и материальными носителями соответствующей информации о создавшем их обществе.

В этом плане все объекты историко-культурного наследия могут рассматриваться нами или как памятники культуры, или как памятники истории (хотя различие это весьма условно и ситуативно). Каждый объект, как памятник культуры, воспринимается закономерным звеном в процессе эволюции определенного направления в культуре. Он совершенствует предыдущие и предваряет его последующие этапы развития. В то же время, если памятник культуры синхронизируется с конкретными историческими событиями прошлого, мы воспринимаем его как памятник истории. Например, сабля Богдана Хмельницкого связывается нами с личностью знаменитого гетмана, но в случае выставления нами других акцентов эта же сабля позволяет охарактеризовать определенный этап развития конструкции холодного оружия.

10 Семенов Е.К. Дисциплинарный статус культурологии. Наука и ее место в культуре. Новосибирск, 1990. С. 99. 
Исследуя материальные объекты прошлого, мы получаем сведения об уровне развития общества, которое их создавало. Особенно это важно в отношении дописьменного периода истории, относительно которого других способов получения объективной информации не существует (в частности, для такой науки, как археология) ${ }^{11}$. В целом, методами получения и оценки знаний о прошлом обществе на основе созданных им артефактов занимается вспомогательная историческая наука источниковедение. Оно рассматривает артефакты прошлых лет именно как источник исторических знаний. Это необходимый этап преобразования имеющихся артефактов в объекты культурного наследия, но памятниковедение этим не ограничивается. Памятниковедение, используя артефакты прошлого для получения научной информации, прежде всего, акцентирует внимание на включении их в современный культурный контекст. Именно в этом случае артефакты прошлого выступают в качестве объектов историко-культурного наследия и формируют уважительное отношение к результатам труда предыдущих поколений. Появляется возможность не просто понять, но и ощутить, что ты наследник прошлого, внутренне принять. Благодаря такому историко-культурному наследию, возможно создание будущего.

Использование указанных артефактов именно как объектов историкокультурного наследия позволяет решить одну из важнейших задач современного общества - социализацию индивидов ${ }^{12}$. Происходит превращение индивида в активный составной элемент общества, который, благодаря своей социализации, обеспечивает существование общества как некоторой целостности. Важнейшей составляющей социализации является эмоциональное включение индивида в социум, что предусматривает определение им своих личностных социально-исторических координат в многомерном социально-историческом континууме. Происходит это не только за счет рационального знания, но и через эмоциональные ощущения. Человек не может существовать как изолированный индивид, ему мало даже наиболее полного набора сведений об условиях функционирования общества. Человек должен стремиться действовать в качестве активного элемента общества. Достижение данного результата возможно только посредством социализации личности, осуществление которой происходит благодаря некоторым особенностям процесса получения и усвоения индивидом информации.

Общепризнано, что социализация личности в основном достигает своих целей к периоду гражданской зрелости человека и в последующем продолжается всю жизнь. Зрелость как раз и означает, что человек усвоил основные социальные роли, которые он должен играть в обществе. Однако и в дальнейшем, фактически в течение всей жизни, человек осваивает новые роли, связанные с изменениями возрастного, профессионального и социального статуса (или вносит коррективы в имеющиеся).

Следовательно, чтобы стать и оставаться активным элементом общества, человеку не достаточно получать определенные знания. Накопленные знания должны превращаться в сознании индивида в прочные убеждения, диктующие ему поведение, отвечающее не только его личным, но и общественным вызовам. Наиболее мощным социальным инструментом для их формирования является искусство. Что

\footnotetext{
11 Давня історія України: у 3-х томах / голова ред. кол. П.П. Толочко. Т. 1: Первісне суспільство / Відповід. ред. В.Н. Станко. Київ: Наукова думка, 1997. 560 с.

12 Мудрик А.В. Социализация человека. Москва: Академия, 2004. 304 с.
} 
касается непосредственной связи с прошлым, то в этом доминантную роль играют памятники истории и культуры. Отметим, что все указанные нами формы социализации предусматривают особый характер передаваемой в обществе информации.

Позитивная результативность совместных действий членов общества возможна только на основе взаимной информированности о целях, возможностях, планах действий, передаче сведений о свойствах предметов и явлений, на которые эти действия направлены. Такая информация, создавая основы для формирования программы действий, предусматривает и определенный импульс к ним. Такой импульс, побуждающий членов общества к действию, создают эмоции, основанные на другом типе информации. Соответственно, человек для формирования своего поведения пользуется, с одной стороны, информацией рационально-логического, а с другой эмоционального характера.

Важность эмоциональной составляющей в жизни человека и, соответственно, в процессе восприятия материальных памятников позволяет нам обратиться к концептуальным акцентам на эту тему ученых прошлого. В XVIII ст. на роль эмоций в жизни человека обратил внимание французский литератор, философ-материалист утилитарного направления К. Гельвеций. Он считал, что даже рациональная умственная активность во многом зависит от эмоций: «...ум, - писал он, - остается бездействующим, пока страсти не приведут его в движение»13. Именно «Эмоция, - говорил И. Павлов, - это то, что направляет вашу деятельность, вашу жизнь»14. Представители философских школ достаточно давно выделяют два вида отношений человека к окружающему миру и рассматривают их как нечто обособленно существующее (чистый разум) и во взаимосвязи с ним (эстетический вкус) ${ }^{15}$. И. Кант считал различными по своей природе логические и эстетические суждения. Он утверждал, что «суждение вкуса не есть познавательное суждение; значит, оно не логическое, а эстетическое» 16 .

Таким образом, существование общественного организма обеспечивается, кроме рационально-логического отношения, еще и наличием у человека некоторых «социальных» эмоций, среди которых особое место занимают эмоции эстетические.

В XX в. в научных исследованиях выделено, в этом контексте, два различных вида информации. Доктор физики и философии, психолог А. Моль (возглавлял Институт социально-психологических проблем коммуникации в Страсбурге, 1920-1992 гг.) одним из первых установил и проанализировал связи между эстетикой и теорией информации. В работе «Теория информации и эстетическое восприятие» он осуществил разделение информации, полученной человеком, на два вида. А. Моль классифицирует информацию как семантическую и эстетическую с точки зрения наблюдателя - «источник-канал-приемник». На основе теоретического анализа делается вывод, что «семантическая информация, подчиняющаяся универсальной логике..., подготавливает действия», а эстетическая информация - это «персональная» информация, которая «не ставит целью подготовить принятие решения преемником...

\footnotetext{
13 Гельвеций К.А. Об уме. Москва: ОГИЗ, 1938. С. 263.

14 Павлов И.П. Павловские клинические среды: стенограммы заседаний в нервной и психиатрической клиниках: в 3 т.: 1931-1933. Москва-Ленинград: Изд-во АН СССР, 1954. Т. 1. 644 с.

15 Батте Ш. Начальные правила словесности: в 4 т. / пер. Д. Облеухов. Москва, 1806. Т. 1. С. 35.

16 Кант И. Критика способности суждения / пер. Н.М.Соколова, Санкт-Петербург: Изд. М.В. Попова, 1898. С. 42.
} 
Эстетическое ни в коей мере не носит утилитарного характера»17.

Эстетическое отношение к миру свойственно человеку как существу общественному, и, соответственно, утилитарно-полезное для общества воспринимается индивидом как нечто позитивное для него, доставляющее ему наслаждение. Эстетическое отношение, наряду с рационально-логическим мышлением являющееся высшей, сугубо человеческой формой отражения, позволяет эмоционально оценивать тот или иной предмет, явление, ситуацию с точки зрения их общественного значения.

Таким образом, применительно к информации, которую получает индивид, целесообразно рассматривать два ее вида, взаимодополняющих друг друга. Информация семантическая базируется на оценке прагматических свойств объектов и подчиняется законам формальной логики. Это чрезвычайно важная информация, ибо в результате ее рационально-логической обработки человеком формируется программа действий в тех или иных условиях.

В то же время, по словам академика А. Колмогорова, автора новаторских работ по истории, философии, методологии и преподаванию математики, одного из основоположников современной теории вероятностей, «в развитом сознании современного человека аппарат формального мышления не занимает центрального положения. Это скорее некоторое «вспомогательное вычислительное устройство», запускаемое по мере надобности» 18 . Данное «устройство» запускается посредством эмоций, отражающих ценностную ориентацию человека. Безусловно, к ним относятся и эмоции эстетические, однако они их не исчерпывают.

Необходимо в целом говорить о базирующейся на эмоциональном отношении к миру аксиологической (ценностной) информации 19 . Возможность эмоционально определить свои социально-исторические координаты, ощутить генетическую связь с прошлым дает только аксиологическая информация, которую несет памятник истории и культуры. Это, прежде всего, аутентичная вещь в своей «телесной» реальности, ибо только в таком контексте человек непосредственно воспринимает прошлое. Именно поэтому в отношении памятников истории и культуры без семантической составляющей информации, включающей данный объект в определенный исторический контекст, обойтись невозможно. Но здесь она подчинена главной цели - созданию и «внедрению» ощущения духовного единства современников с прошлым. В то же время для памятника главным является не столько научная информация, которую он может предоставить, сколько воплощение в нем духовной сути предков, конкретное материальное «опредмечивание» их социального и исторического бытия.

Психологически человек всегда сознательно или подсознательно чувствует себя находящимся в определенной системе пространственных, временных и социальных координат. Только это дает ему возможность считать себя конкретной личностью. Такая система координат отображает то, что сложилось в мозгу человека, в его памяти на основе внешних воздействий в течение всей жизни. Однако память, как свидетельствуют научные исследования, - система ограниченная и ненадежная. Поэтому априори существует стремление опереться на определенные материаль-

\footnotetext{
17 Моль А. Теория информации и эстетическое восприятие. Москва: Мир, 1966. С. 203-204.

18 Колмогоров А.Н. Автоматы и жизнь. Возможное и невозможное в кибернетике / под ред.:

А.И. Берга, Э.Я. Кольмана. Москва: Наука, 1964. С. 26.

19 Ильин В.В. Аксиология. Москва: Изд-во МГУ, 2005. 216 с.
} 
ные свидетельства, подтверждающие действительность принятых социальноисторических координат. Своеобразными «реперными точками» траектории движения в том социально-временном континууме, в котором существует каждое новое поколение, и являются объекты историко-культурного наследия. Каждый индивид связывает себя эмоционально с реальностью через непосредственное восприятие аутентичных предметов, включенных в исторический контекст определенного времени.

Памятники истории и культуры следует признать одним из важнейших факторов социализации индивида путем как сознательного, так и подсознательного определения им своего места в целостном процессе социального развития. Памятники истории и культуры (как недвижимые, так и те, что находятся в собраниях музеев) играют специфическую роль. Главным является материальное «опредмечивание» прошлого социального и исторического бытия социума. Достижение этой цели основная прерогатива музея как социального института, в реализации которой ни один другой социальный институт заменить его не может. Известный австрийский теоретик музейного дела Ф. Вайдахер подчеркивал: «Музеи... были созданы для того, чтобы помочь всем заинтересованным лучше понять себя и свое место в этом мире» 20 .

Специфическая роль музея как социального института базируется именно на использовании аутентичных объектов историко-культурного наследия для комплексного и целенаправленного воздействия на индивида. «Знание и опыт, - считают специалисты музееведения, - можно передавать по-разному, но ни одно учреждение не сравнится с музеями, обладающими уникальной возможностью воздействовать на все многообразие человеческих чувств: зрение, слух, осязание, обоняние, даже вкус, ориентацию в пространстве». Именно музеи «сочетают передачу знаний с эстетическим и эмоциональным воспитанием, они пробуждают в человеке творческое начало, и в этом нет им равных»21. Известный музеевед С. Странский рассматривал современный музей как важную форму институционализации специфического отношения человека к действительности с целью объединить прошлое с настоящим. Эта специфика, считал он, «проявляется в стремлении к приобретению и сохранению, несмотря на естественные тенденции изменения и исчезновения, истинных ценностей, сохранение и использование которых создает и умножает гуманистический и культурный облик человека»22.

Музеи по роли и восприятию аксиологической информации близки к искусству. В научной литературе вполне обоснованно транслируются сопоставительные алгоритмы музейного дела с искусством. Напомним, что именно искусство как социальное явление и творческая деятельность в значительной мере обеспечивает социализацию индивида. Погружение в его различные сферы позволяет человеку ощутить себя составным элементом отдельных социальных образований. В конце XIX ст. на концептуальное значение искусства обратил внимание Л. Толстой: «Все, что теперь, независимо от страха насилия и наказания, делает возможным совокуп-

\footnotetext{
20 Вайдахер Ф. Загальна музеологія: посібник / перекл. 3 нім. В. Лозинський, О. Лянг, Х. Назаркевич. Львів: Літопис, 2005. С. 16.

21 Нильсон Б., Росен Б. Экология человека и культурно-исторические музеи. Museum. 1989. № 160. C. 50.

22 Странский С. Понимание музееведения. Музееведение. Музеи мира: Сб. науч. тр. НИИ культуры. Москва, 1991. С. 19.
} 
ную жизнь людей... все это сделано искусством»²3. Аналогичные акценты закономерны и относительно музейного дела, поскольку оно также ставит целью социально-значимое влияние на индивида. И все же их социально-обусловленные цели разные. Если искусство способствует превращению нас в элементы социума как таковые, то музеи помогают нам осознать себя этими его элементами и определить свои социально-исторические координаты в нем. Музеи помогают индивиду связать свое существование с развитием определенных социальных образований во времени и пространстве - каждого в частности и социума как целого вообще. Следовательно, социальная роль музеев не может выполняться никакими другими институтами. А комплексная реализация музеями этой функции возможна только с помощью определенных музейных предметов, в качестве которых выступают памятники истории и культуры.

Таким образом, музейные артефакты, как и другие материальные памятники духовной культуры, решают важнейшие вопросы социализации человека как активного члена общества. Социализация в качестве одного из важнейших элементов «для эмоционального включения» в социум как раз и предполагает эмоциональное определение индивидом своих личностных координат, которые без «погружения» в прошлое для создания внутреннего ощущения родства с ним достичь невозможно.

Выводы. Таким образом, определенный артефакт, пришедший к нам из прошлого, становится своеобразным носителем двух «ипостасей». С одной стороны, он остается предметно-материальным образованием, созданным человеком с конкретной целью - для выполнения определенных технологических функций. Таких функций может быть две: взаимодействие с окружающей средой и передача материальных средств или информационных потоков внутри общества. С другой стороны, относительно современности данное материальное образование (артефакт) выступает носителем информационного потока и несет как рационально-логическую, так и аксиологическую (эмоциональную) информацию. Информацию о том обществе, которое создавало и использовало в утилитарных целях данное материальное образование. Дошедшие до нас из прошлого материальные результаты деятельности человека уже визуально воспринимаются как памятники его истории и культуры. Они не только предоставляют некоторые сведения, но и обеспечивают субъекту эмоциональную возможность «окунуться» в прошлое.

Указанное «погружение» возможно только тогда, когда субъект эмоционально связывает себя с прошлым, то есть за счет аксиологической информации. В силу специфики эта информация не может быть получена опосредованно - только в процессе непосредственного восприятия объекта в его телесности, то есть в виде аутентичного памятника. Достичь необходимого результата можно лишь связав данный материальный объект с контекстом определенного времени путем использования исторического тезауруса, созданного с помощью всех доступных исторических источников (чем, в частности, занимается источниковедение). Совместно эти процессы и создают феномен историко-культурного наследия.

\section{REFERENCES}

Antonovych, V.B. (2003). Lektsii z dzhereloznavstva [Lectures on Source Studies]. Kyiv: Nats. un-t Ostrozka akademiia [in Ukrainian].

23 Толстой Л.Н. Что такое искусство? Полное собрание сочинений в 90 томах. Т. 30. Москва: Изд-во Худ. лит., 1951. С. 194-195. 
Battio, Sh. (Ed.) (1806). Nachalnye pravila slovesnosti [The initial rules of literature]. (Vols. 1-4). Moskva [in Russian].

Boiarskiy, P.V. (1990). Vvedenie v pamiatnikovedenie. [Introduction to Monumental Science]. Kyiv [in Ukrainian].

Dulov, 0. (1993). Pamiatkoznavstvo yak nauka [Monumental Science as a science]. Pamiatky Ukrainy, 16, 139, 203-204 [in Ukrainian].

Helvetsyi, K.A. (1938). Ob ume [About the Mind]. Moskva [in Russian].

Il'in, V.V. (2005). Aksiolohiia [Axiology]. Moskva [in Russian].

Kant, I. (1898). Kritika sposobnosti suzhdeniia [A Critique of the Capacity for Judgment]. SanktPeterburg: Izd. M.V. Popova [in Russian].

Kolmohorov, A.N. (1964). Avtomaty i zhizn [Machines and Life]. In Berh, A.Y. \& Kolman, E.Ya. (Eds). Vozmozhnoie i nevozmozhnoie v kibernetike (p. 26). Moskva: Nauka [in Russian].

Kostiuk, V.N. (1993). Izmeniaiushchiesia sistemy [Changing Systems]. Moskva: Nauka [in Russian].

Kot, S. (2007). Teoretychni problemy pamiatkoznavstva [Theoretical problems of Monument's Studies]. Pamiatkoznavchi studii v Ukraini: teoriia i praktyka (pp. 7-64). Kyiv [ in Ukrainian].

Mol', A. (1966). Teoriia informatsii i esteticheskoe vospriiatie [Information Theory and Esthetic Perception]. Moskva: Mir [in Russian].

Mudrik, A.V. (2004). Sotsializatsiia cheloveka [Human socialization]. Moskva [in Russian].

Nilson, B. \& Rosen, B. (1989). Ekolohiia cheloveka i kulturno-istoricheskie muzei [Human Ecology and Cultural History Museums]. Museum, 160, 50 [in Russian].

Pavlov, Y.P. (1954). Pavlovskie klinicheskie sredy: stenohrammy zasedaniy v nervnoi i psikhiatricheskoi klinikakh [Pavlovian Clinical Environments: Transcripts of Sessions in Nursing and Psychiatric Clinics]. (Vol. 1-3) Moskva-Leninhrad: Izdatelstvo AN SSSR [in Russian].

Rudenko, S.P. (2008). Pro fundamentalni zasady pamiatkoznavstva [About the Fundamental Principles of Monuments Studies]. Pratsi Tsentru pamiatkoznavstva, 14,18-40 [ in Ukrainian].

Senchenko, N.M. \& Titova, M.O. (Eds). (2019). Kulturna spadshchyna yak skladova derzhavnoi osvitnovykhovnoi polityky $v$ Ukraini [Cultural heritage as a component of State educational policy in Ukraine]. Nizhyn [in Ukrainian].

Semenov, E.K. (1990). Distsyplinarnyi status kulturolohii [The Disciplinary Status of Culturology]. Nauka i eio mesto v culture (pp. 88-104). Novosibirsk [in Russian].

Shredinher, E. (1972). Chto takoe zhizn's tochki zreniia fizika? [What is Life from the Point of View of a Physicist?]. Moskva [in Russian].

Stranskiy, C. (1991). Ponimanie muzeevedeniia [Understanding Museum Studies] Muzeevedenie. Muzei mira (pp. 8-26). Moskva [in Russian].

Tolochko, P.P. (Ed.) (1997). Davnia istoriia Ukrainy [Ancient History of Ukraine]. Vol. 1. Kyiv: Naukova dumka [in Ukrainian].

Tolstoi, L.N. (1951). Chto takoe iskusstvo? [What is Art]. In Polnoe sobranie sochineniy (Vol. 30). Moskva: Izdatelstvo Khudozhestvennoi Literatury [in Ukrainian].

Vaidakher, F. (2005). Zahalna muzeolohiia [General Museology]. Lviv: Litopys [in Ukrainian].

Zaremba, S.Z. (1995). Ukrainske pamiatkoznavstvo: istoriia, teoriia, suchasnist [Ukrainian Monuments Studies: History, Theory, Modernity]. Kyiv [in Ukrainian].

\section{Leonid Griffen}

(National Historical and Architectural Museum «Kyiv Fortress», Kyiv, Ukraine)

e-mail: lagrif@mail.ru

ORCID: https://orcid.org/0000-0002-3020-9636

\section{Nadiia Ryzheva}

(Mykolaiv national university by name of V.O. Sukhomlynskyi, Mykolaiv, Ukraine)

e-mail: ryzheva.nadiya@gmail.com

ORCID: https://orcid.org/0000-0001-8379-4325

\section{Historical and Cultural Heritage as Social Phenomenon}

The study of the social nature of historical and cultural heritage, which is one of the most essential goals of a relatively young science - Monument Studies, is presented. It is shown that 
it characterizes the objects of the material culture of the past which have lost their original utilitarian purpose and have turned into material evidence of elapsed cultural and historical processes. Today, such historical and cultural monuments are the bearers of semantic and axiological information about certain processes, and therefore, being included in the modern cultural context, they contribute to the socialization of the individuals. Because of the specific character of the axiological information, it cannot be obtained indirectly, but only in the process of direct perception of an object in its materiality, that is, in the form of an authentic monument. The key feature of the monument as a historical and cultural heritage is not so much the scientific information that it can give, but the embodiment of the spiritual essence of the ancestors in it, the certain material objectification of their social and historical existence. This provides a kind of immersion in the past, with which the individual connects himself emotionally through the direct perception of an authentic object included in the historical context of a certain time.

The paper draws attention to the fact that all of us, determining the trajectories of our movement in that socio-temporal continuum where we exist, consider the objects of our historical and cultural heritage as some kind of reference points. The monuments of history and culture (both immovable and those which are in museum collections) play a specific role in this process. The main thing is the material perception of the past of society's social and historical existence. The main prerogative of the museum as a social institution is in achieving this goal, in implementing of which no other social institution can replace it.

It is proved in the paper that to establish the relationship of the individual with the past, the knowledge got from historical sources in the process of analyzing scientific information about the object is not enough. Such information is sufficient if we speak only about the cognition of the past. But, if the task of forming a person as an active member of society is realized, it is impossible to succeed without the axiological information gained directly from the object of historical and cultural heritage, and this defines historical and cultural heritage as a particular social phenomenon.

Keywords: Monument Studies, historical and cultural heritage, historical and cultural monuments, socialization of an individual, semantic information, axiological information 